\title{
Psychiatric Comorbidity in Patients with Acne
}

\author{
Amir Mufaddel ${ }^{1 *}$, Asim Ahmed Elnour ${ }^{2,3 \#, ~ A b d e l a z i z ~ A . ~ O m e r ~}{ }^{4}$, Esam H. Alshora1 \\ ${ }^{1}$ Alkharj Psychiatric Hospital, Riyadh, KSA \\ ${ }^{2}$ Faculty, Pharmacy Program, Fatima College of Health Sciences, Abu Dhabi/Al Ain, UAE \\ ${ }^{3}$ Monash University, Melbourne, Australia \\ ${ }^{4}$ Faculty of Medicine, Department of Psychiatry, University of Khartoum, Khartoum, Sudan \\ Email: *khalifaamir@yahoo.co.uk
}

How to cite this paper: Mufaddel, A., Elnour, A.A., Omer, A.A. and Alshora, E.H. (2017) Psychiatric Comorbidity in Patients with Acne. Open Journal of Psychiatry, 7, 176-185.

https://doi.org/10.4236/ojpsych.2017.73016

Received: May 20, 2017

Accepted: July 17, 2017

Published: July 20, 2017

Copyright $\odot 2017$ by authors and Scientific Research Publishing Inc.

This work is licensed under the Creative

Commons Attribution International

License (CC BY 4.0).

http://creativecommons.org/licenses/by/4.0/

\begin{abstract}
Acne vulgaris is a chronic inflammatory skin disorder which has a high prevalence among adolescents and young adults and can be associated with emotional and psychological burden on patients. This review aimed to explore psychological factors in patients with acne. Several forms of emotional distress and psychological complications can occur with acne. Such complications may be worse than the physical impact of the skin condition. Current literature suggests that skin changes in acne are associated with changed body image, psychological distress, anxiety, social phobia, suicidal ideation and depression. Population-based studies suggest a significant association between acne and mental distress among both male and female adolescents. Presence of psychological distress is related to severity of acne in some studies. However, other case-controlled studies suggest increased risk for psychological problems in patients with acne regardless of its severity. Stress is suspected to have a role in exacerbations of acne, and the quality of life (QoL) is affected particularly in cases with severe facial acne. Acne treatment can be associated with psychiatric side effects. Isotretinoin may be associated with depression and suicide attempts as shown in several studies but with conflicting results. On the other hand, psychotropic medications (such as antidepressants, antipsychotics and mood stabilizers) can also induce acne. The results of this review indicate the importance of vigilant psychiatric assessment for patients with acne, particularly those receiving isotretinoin, is needed for early diagnosis and treatment of the associated psychiatric co-morbidity.
\end{abstract}

\section{Keywords}

Acne, Anxiety, Depression, Isotretinoin, Psychodermatology, Stress, Suicide

\section{Introduction}

The skin is the initial point of contact between the internal and external envi-

\#Adjunct Clinical Associate Professor. 
ronments. Exposure to external pollutants, toxins, allergens and other noxious environmental elements are expressed through the skin [1]. On the other hand, emotional factors can affect the outcome of some dermatological conditions. It has been estimated that, in at least one third of patients with dermatological conditions, considering the associated emotional factors is essential for effective management of the skin disorder [2]. Koo and Lee classified psychodermatological conditions into three main categories: 1) Psychophysiological disorders; 2) Psychiatric disorders with dermatological symptoms; and 3) Dermatological disorders with psychiatric symptoms. The term psychophysiological disorders refer to skin disorders that are worsened by emotional stress (such as eczema, acne and psoriasis). In primary psychiatric disorders, e.g. trichotillomania, the primary condition is psychological and the skin manifestations are secondary to the psychiatric condition, in such conditions the symptoms can be self-induced. Secondary psychiatric disorders develop as a consequence of a disfiguring skin lesion that has negative impact on the patient's self-esteem, body image and mood. This can lead to feelings of humiliation, frustration and social anxiety [3] [4]. The impact of the skin disorder on the patient's quality of life is thought to be strong predictor of psychiatric morbidity than the clinical severity of the skin condition. Therefore, the psychiatric co-morbidity is an important measure contributing to the overall disability experienced by the patient [5].

In this paper, we are discussing the comorbid psychiatric disorders in patients who are suffering from acne, as well as the impact of medications that are used for its treatment on the patient's psychological status.

\section{Acne Vulgaris}

Acne vulgaris is a chronic inflammatory disorder of the pilosebaceous unit, it is a very common skin condition that affects at least $85 \%$ of adolescents and young adults [6] [7]. In a large study including more than thousand adolescents, the prevalence of acne was found as high as $93.3 \%$ [8]. Symptoms and signs of acne are related to distended, inflamed, or scarred pilosebaceous units, mainly characterized by polymorphic lesions, that are most commonly seen on the face, back and the chest. Seborrhoea is the most frequently occurring feature. Distended pilosebaceous units can take the form of open or closed comedones, and the types of inflamed lesions exhibited are pustules, papules, nodules, and cysts. More severe forms can occur with multiple inflammatory papules and nodules that fuse to form draining sinuses; and this can lead to chronic scarring. Malignant changes are rarely occurring; for example there were two reported cases of squamous cell carcinoma complicating longstanding acne conglobata in a father and daughter with fatal outcome in both cases. Post-inflammatory hyperpigmentation is commonly seen in pigmented skin [9] [10].

In this paper, we review the possible relations between acne and various psychological factors. These relations can take several forms. For example: 1) acne can be associated with major psychiatric disorders such as depression and an- 
xiety disorders; 2) Psychological factors such as stress can exacerbate acne; 3) Emotional stress such as anger, embarrassment, and shame can occur secondary to acne; 4) medications that are used for treatment of acne can lead to psychiatric side effects including depression and suicidal thoughts; and 5) psychotropic medications can induce acne. These forms of relation are summarized in Table 1.

\section{Mental Health Problems in Patients with Acne}

Acne can lead to variable forms of emotional distress and psychological compli-

Table 1. Summary of the relation between acne, psychological factors and side effects of medication.

\begin{tabular}{|c|c|}
\hline $\begin{array}{c}\text { The form of relation between acne } \\
\text { and Psychological factors }\end{array}$ & Comments \\
\hline $\begin{array}{l}\text { Major psychiatric disorders associated } \\
\text { with acne: } \\
\text { Depression } \\
\text { Anxiety disorders } \\
\text { Social phobia } \\
\text { Body dysmorphic disorder }\end{array}$ & $\begin{array}{l}\text { The highest incidence of depression and suicidal } \\
\text { ideation in dermatology patients was reported with } \\
\text { those who have severe forms of acne and psoriasis } \\
\text { [11] [12] [13] [19] [20]. } \\
\text { Anxiety disorders in general and social phobia (social } \\
\text { anxiety) in particular are more common in patients } \\
\text { with acne than control subjects [12] [13] [15] [20] } \\
\text { [21]. }\end{array}$ \\
\hline $\begin{array}{l}\text { Psychological factors affecting the } \\
\text { course of acne: } \\
\text { e.g. the role of stress in exacerbation of } \\
\text { acne }\end{array}$ & $\begin{array}{l}\text { Psychological factors can affect the course of skin } \\
\text { diseases and acne can be exacerbated following } \\
\text { stressful situations. There are some theories trying to } \\
\text { explain the role of stress in exacerbations of acne } \\
\text { such as Brain-Gut-Skin theory [1] [18] [19]. }\end{array}$ \\
\hline $\begin{array}{l}\text { Other psychological problems } \\
\text { secondary to skin conditions: } \\
\text { Impact on quality of life } \\
\text { Psychological distress reflected in } \\
\text { emotional problems (e.g. shame, anger, } \\
\text { embarrassment...etc.) }\end{array}$ & $\begin{array}{l}\text { The quality of life of patients with acne can be as } \\
\text { severely affected as those with other chronic medical } \\
\text { conditions. } \\
\text { The change in the skin's appearance may be complicated } \\
\text { by a changed body image, psychological distress, } \\
\text { anger, fear, shame, embarrassment, and bullying and } \\
\text { stigmatization within peer groups [9] [35] [36] [37] } \\
\text { [38] [39]. }\end{array}$ \\
\hline $\begin{array}{l}\text { Psychiatric side effects of medications } \\
\text { used for treatment of acne: } \\
\text { E.g. risk of depression and suicidal } \\
\text { thoughts due to use of isotretinoin }\end{array}$ & $\begin{array}{l}\text { Isotretinoin is a vitamin A derivative which is } \\
\text { approved for treatment of severe acne. It can limit } \\
\text { or prevent scarring and decrease the length of the } \\
\text { condition resulting in significant psychosocial } \\
\text { improvement [22] [23] [24]. However, isotretinoin } \\
\text { is reported among the Food and Drug } \\
\text { Administration's (FDA) } 10 \text { top drugs to be } \\
\text { associated with depression and suicidal attempts } \\
\text { [25]. }\end{array}$ \\
\hline $\begin{array}{l}\text { Acne as side effect of psychotropic } \\
\text { medications: } \\
\text { Antidepressants, } \\
\text { Antipsychotics } \\
\text { Anticonvulsants and mood stabilizers }\end{array}$ & $\begin{array}{l}\text { Psychotropic medications can cause drug-induced } \\
\text { acne such as trazodone, haloperidol, lithium and } \\
\text { aripiprazole. Anticonvulsants may be associated with } \\
\text { skin rash, alopecia, acne eruptions, erythema multiforme, } \\
\text { psoriasis and pruritus, while lamotrigine may be } \\
\text { associated with life threatening Stevens-Johnson } \\
\text { syndrome [42] [43] [44] [45] [46] }\end{array}$ \\
\hline
\end{tabular}


cations that may be worse than the physical impact of the skin condition. The change in the skin' s appearance may be complicated by a changed body image which may lead to psychological distress, anxiety, depression, anger, fear, shame, embarrassment, and bullying and stigmatization within peer groups [9]. In a general population-based study including adolescents, there was a significant association between acne and mental distress among both males and females. The severity of mental distress is related to the increase of symptoms' severity according to this study [11]. However, a recent case-controlled study concluded that irrespective of the degree of severity, patients with acne are at increased risk for psychological problems including anxiety and depression compared to the normal population. The rates of subjects who are at increased risk for anxiety (26.2\%) and for depression (29.5\%) were significantly higher in the patient group than in the control group ( $0 \%$ and $7.9 \%$, respectively) [12].

Comparing depressive symptoms in various dermatological conditions revealed that the highest incidence of depression and suicidal ideation was found in patients with severe forms of acne and severe psoriasis [2]. In a case -controlled study that used the Hospital Anxiety and Depression Scale (HADS) to assess anxiety and depression in several dermatological conditions, HADS scores for anxiety were significantly higher in patients with psoriasis, vitiligo, acne and eczema compared with healthy subjects [13].

Some studies suggest that depression is 2 to 3 times more prevalent in patients with acne than in the general population. About $8.8 \%$ of acne patients have shown symptoms that are sufficient to fulfill the criteria for the clinical diagnosis of depression, which is more commonly seen in female patients [14]. A study of large sample size including more than nine thousand adolescents in New Zealand, found an association between acne and increased probability of depressive symptoms (odds ratio 2.04), anxiety (odds ratio 2.3), and suicidal attempts (odds ratio 1.83). This finding suggests that young people presenting with acne are at increased risk of depression, anxiety and suicidal attempts [15]. Acne affects young people when they are highly concerned with their social and physical characteristics, and it may also have a negative effect on the way that people are perceived by others. Teenagers with acne were perceived by others as generally being shy, less socially active, more likely to be bullied, and less successful in terms of finding a job. Acne can be complicated with various forms of body image disorders. For example, eating disorders and dysmorphophobia (body dysmorphic disorder) may coexist [16].

Psychological factors can affect the course of skin diseases; and up to $50 \%$ of females with acne suffer flares that occur following stressful situations [17]. There are some theories trying to explain the role of stress in exacerbation of acne. For example, a recent validation of the Brain-Gut-Skin theory which has been suggested over 70 years ago by the dermatologists John Stokes and Donald Pillsbury. The lines of communication, according to this theory, may be directly or indirectly mediated by gut microbes and influence the severity of acne by several mechanisms including systemic effect on inflammation, oxidative stress, 
glycemic control, tissue lipids level, pathogenic bacteria, as well as levels of neuropeptides and mood-regulating neurotransmitters [18]. A prospective cohort study, that aimed to investigate the possible relationship between stress and acne exacerbations, indicated that exacerbations of acne were reported during examination periods in university students. This finding suggest significant influence of emotional stress on acne, which is also supported by the finding that changes in severity of acne was highly correlated with increasing stress [19]. Social phobia is one of the common psychiatric comorbidities among patients with acne vulgaris. In a recent case-control study, social phobia was diagnosed in $45.7 \%$ of patients with acne compared with $18.4 \%$ of control subjects. Patients with acne vulgaris demonstrated higher performance avoidance and total avoidance scores and were also found to be more disabled in their occupational, social, and familial lives [20]. The degree of social anxiety, social avoidance, generalized anxiety, depression, and negative automatic thoughts were significantly higher, and self-esteem was significantly lower in patients with acne [21].

\section{Isotretinoin and Risk of Depression and Suicide}

Isotretinoin (13-cis-retinoic acid) was introduced in 1982 for the treatment of nodular and cystic acne. It is a vitamin A derivative which is approved for treatment of severe acne that is not responding to standard therapy such as systemic antibiotic therapy. Isotretinoin therapy can limit or prevent scarring and decrease the length of the condition, resulting in significant psychosocial improvement [22] [23] [24]. However, isotretinoin is reported among the Food and Drug Administration's (FDA) 10 top drugs to be associated with depression and suicidal attempts [25]. The FDA has received reports of 394 cases of depression, and 37 suicides occurring in patients who were treated with isotretinoin from 1982 to 2000 [26], in addition to 173 reports of suicide that were associated with isotretinoin in 2003 [27]. Bremner and colleagues have outlined evidence for a relationship between isotretinoin and depression including: evidence from case reports in the literature, temporal association, challenge and re-challenge studies, dose response, biological plausibility and class effect. Cases that were reported in the literature indicated presence of mental symptoms associated with vitamin A toxicity. The psychiatric symptoms were reported in the form of irritability, depression, lethargy, mood lability, and psychosis. Development of depression is temporally related to the initiation of treatment with isotretinoin which suggest causal role of isotretinoin in the development of depression. Most of the cases presenting with isotretinoin-induced depression developed after 1 2 months of treatment. (https://www.ncbi.nlm.nih.gov/pubmed/16112443) Higher doses of isotretinoin were found to be associated with a greater risk of depression [28].

Retinoids are known to bind to retinoid receptors in the brain and to exert effects on gene transcription. Retinoid receptors are concentrated in limbic areas which have been associated with depression, including the amygdala, prefrontal cortex, and hippocampus. Retinoids also influence neurochemical systems im- 
plicated in depression, particularly dopamine, and to some extent serotonin and norepinephrine [29].

A retrospective chart review of 300 of patients with bipolar disorder attending outpatient service, has identified ten patients treated with isotretinoin. The review revealed 9 of these 10 patients experienced a significant worsening of mood symptoms, and 3 developed suicidal ideation. Eight experienced improvement of the relapsed mood symptoms when the isotretinoin was discontinued [30]. A recent case-crossover study performed among subjects who received isotretinoin prescription from 1984 through 2003, reported statistically significant association between isotretinoin and depression [31].

There were conflicting results among the studies that aimed to investigate the association between isotretinoin therapy and depression. Many studies found no association between isotretinoin therapy and depression. For example; a study involving 78 acne patients who have received either isotretinoin treatment (study group) or topical treatment (control group), found no increase in depressive and anxiety symptoms in the isotretinoin treatment group compared to that in the topical treatment group using the Hospital Anxiety and Depression Scale (HADS), and the Beck Depression Inventory (BDI) [32]. A prospective cohort Canadian study, conducted in a community dermatology clinic, found no correlation between isotretinoin use and the development of depression. However the study included small number of patients on isotretinoin and the study groups were not randomized [22].

A systematic review of 9 studies has shown that rates of depression among isotretinoin users is ranging from $1 \%$ to $11 \%$ across studies, with similar rates in oral antibiotic control groups. Studies comparing depression before and after isotretinoin treatment did not show a statistically significant increase in depression diagnoses or depressive symptoms [33].

The occurrence of an idiosyncratic reaction to isotretinoin producing major depression and suicidal ideation, as suggested by case studies, remains a possibility. It is crucial to carefully monitor patients receiving isotretinoin for the emergence of depressive symptoms and suicidal ideation during the course of treatment [34].

\section{Quality of Life}

Studies on the quality of life in patients with acne suggested that it is at the same level as patients with other chronic medical conditions including asthma, epilepsy, diabetes, back pain and arthritis [35]. A study including 112 female students with acne concluded that acne clinical severity alone does not affect changes in quality of life that are related to acne. Factors correlated with quality of life include: social factors, emotional factors, personality type, presence of scarring and school-related or job-related problems [36]. Severity of facial acne was found to be correlated with quality of life in adolescents, particularly in male patients [37].

Patients with acne are affected by disturbances in functioning level and emo- 
tional well-being due to their skin problems that are comparable with the effect of skin disease of those with psoriasis, but they may experience fewer symptoms. Older adults reported more effects of acne on their quality of life than reported by younger adult population [38]. The quality of life may be improved by successful treatment of acne that consider providing both clinical and psychological improvement of patients [39].

\section{Management}

Improving knowledge and considering appropriate referrals for integrated management of pychocutaneous disorders as well as education for patients and families on psychocutaneous disorders may help in optimal management and early interventions for both dermatological and psychiatric symptoms [40]. Skin conditions that have strong psychophysiological aspects, such as acne, may respond to some psychological therapy trials such as biofeedback, cognitive-behavior therapy, meditation or progressive relaxation that aim to provide stress management and to counteract stress [41]. In management of patients with co-existing acne and psychiatric symptoms; it is better to avoid psychotropic medications that may cause drug-induced acne such as trazodone, haloperidol, and lithium which can cause or exacerbate acne. There are reported cases of drug-induced acneiform eruptions associated with the use of aripiprazole [42] [43] [44]. Anticonvulsants and mood stabilizers may be associated with skin rash, alopecia, acne eruptions, erythema multiforme, psoriasis and pruritus. Lamotrigine, which is used as mood stabilizer, is known to be associated with life threatening Stevens-Johnson syndrome [45] [46]. Patients who are receiving isotretinoin should be carefully monitored for the possibility of emerging psychiatric symptoms, particularly depression, current suicidal thoughts, and previous suicidal behavior.

\section{Conclusion}

Acne is associated with psychological distress, depression, suicidal ideation and anxiety. Quality of life in patients with acne is affected by emotional and functional burden which may be improved by successful treatment addressing the clinical manifestations and psychological distress. There were conflicting results regarding the association between isotretinoin therapy and emergence of depressive symptoms and suicidal ideation which prompts crucial psychiatric assessment for patients with acne who are receiving isotretinoin. A collaborative approach and integration of dermatological and psychiatric management are needed for better outcomes.

\section{References}

[1] Osman, O.T., Mufaddel, A., Almugaddam, F. and Augusterfer, E.F. (2011) The Psychiatric Aspects of Skin Disorders. Expert Review of Dermatology, 6, 195-209. https://doi.org/10.1586/edm.11.10

[2] Gupta M.A. and Gupta A.K. (1996) Psychodermatology: An Update. Journal of the 
American Academy of Dermatology, 34, 1030-1046. https://doi.org/10.1016/S0190-9622(96)90284-4

[3] Jafferany, M. (2007) Psychodermatology: A Guide to Understanding Common Psychocutaneous Disorders. Primary Care Companion to the Journal of Clinical Psychiatry, 9, 203-213. https://doi.org/10.4088/PCC.v09n0306

[4] Shenefelt, P.D. (2010) Update on Psychodermatological Disorders. Expert Review of Dermatology, 5, 95-107. https://doi.org/10.1586/edm.09.62

[5] Gupta, M.A. and Gupta, A.K. (2003) Psychiatric and Psychological Co-Morbidity in Patients with Dermatologic Disorders: Epidemiology and Management. Journal of the American Academy of Dermatology, 4, 833-842. https://doi.org/10.2165/00128071-200304120-00003

[6] Weiss, J.S. (1997) Current Opinions for the Topical Treatment of Acne Vulgaris. Pediatric Dermatology, 14, 480-488. https://doi.org/10.1111/j.1525-1470.1997.tb00696.x

[7] Krowchuck, D.P. (2000) Managing Acne in Adolescents. Pediatric Clinics of North America, 47, 841-857. https://doi.org/10.1016/S0031-3955(05)70243-1

[8] Ghodsi, S.Z., Orawa, H. and Zouboulis, C.C. (2009) Prevalence, Severity, and Severity Risk Factors of Acne in High School Pupils: A Community-Based Study. Journal of Investigative Dermatology, 129, 2136-2141. https://doi.org/10.1038/jid.2009.47

[9] Ayer, J. and Burrows, N. (2006) Acne: More than Skin Deep. Postgraduate Medical Journal, 82, 500-506. https://doi.org/10.1136/pgmj.2006.045377

[10] Whipp, M.J. and Dundas, S. (1987) Fatal Squamous Cell Carcinoma Associated with Acne Conglobata in a Father and Daughter. The British Journal of Dermatology, 117, 389-392. https://doi.org/10.1111/j.1365-2133.1987.tb04148.x

[11] Halvorsen, J.A., Dalgard, F., Thoresen, M., Bjertness, E. and Lien, L. (2009) Is the Association between Acne and Mental Distress Influenced by Diet? Results from a Cross-Sectional Population Study among 3775 Late Adolescents in Oslo, Norway. BMC Public Health, 16, 340. https://doi.org/10.1186/1471-2458-9-340

[12] Yazici, K., Baz, K. and Yazici, A.E. (2004) Disease-Specific Quality of Life Is Associated with Anxiety and Depression in Patients with Acne. Journal of the European Academy of Dermatology and Venereology, 18, 435-439. https://doi.org/10.1111/j.1468-3083.2004.00946.x

[13] Mufaddel, A. and Abdelghani, E. (2014) Psychiatric Comorbidity in Patients with Psoriasis, Vitiligo, Acne, Eczema and Group of Patients with Miscellaneous Dermatological Diagnoses. Open Journal of Psychiatry, 4, 168-175. https://doi.org/10.4236/ojpsych.2014.43022

[14] Uhlenhake, E., Yentzer, B.A. and Feldman, S.R. (2010) Acne Vulgaris and Depression: A Retrospective Examination. Journal of Cosmetic Dermatology, 9, 59-63. https://doi.org/10.1111/j.1473-2165.2010.00478.x

[15] Purvis, D., Robinson, E., Merry, S. and Watson, P. (2006) Acne, Anxiety, Depression and Suicide in Teenagers: A Cross-Sectional Survey of New Zealand Secondary School Students. Journal of Paediatrics and Child Health, 42, 793-796. https://doi.org/10.1111/j.1440-1754.2006.00979.x

[16] Ritvo, E., Del Rosso, J.Q., Stillman, M.A. and La Riche, C. (2011) Psychosocial Judgements and Perceptions of Adolescents with Acne Vulgaris: A Blinded, Controlled Comparison of Adult and Peer Evaluations. BioPsychoSocial Medicine, 5, 11. https://doi.org/10.1186/1751-0759-5-11

[17] Koo, J.Y. and Pham, C.T. (1992) Psychodermatology, Practical Guidelines on Pharmacotherapy. Archives of Dermatology, 128, 381-388. 
https://doi.org/10.1001/archderm.1992.01680130095013

[18] Bowe, W.P. and Logan, A.C. (2011) Acne Vulgaris, Probiotics and the Gut-BrainSkin Axis-Back to the Future? Gut Pathogens, 3, 1. https://doi.org/10.1186/1757-4749-3-1

[19] Chiu, A., Chon, S.Y. and Kimball, A.B. (2003) The Response of Skin Disease to Stress: Changes in the Severity of Acne Vulgaris as Affected by Examination Stress. Archives of Dermatology, 139, 897-800. https://doi.org/10.1001/archderm.139.7.897

[20] Bez, Y., Yesilova, Y., Kaya, M.C. and Sir, A. (2011) High Social Phobia Frequency and Related Disability in Patients with Acne Vulgaris. European Journal of Dermatology, 21, 756-760.

[21] Yolaç, Y.A., Demirci, S. E., Erdi, S.H. and Devrimci, O.H. (2008) Social Anxiety Level in Acne Vulgaris Patients and Its Relationship to Clinical Variables. Turkish Journal of Psychiatry, 19, 29-37.

[22] Cohen, J., Adams, S. and Patten, S. (2007) No Association Found between Patients Receiving Isotretinoin for Acne and the Development Depression in a Canadian Prospective Cohort. The Canadian Journal of Clinical Pharmacology, 14, 227-233.

[23] Layton, A.M. (1998) Psychosocial Aspects of Acne Vulgaris. Journal of Cutaneous Medicine and Surgery, 2, S19-S23.

[24] Hong, C. and Schweitzer, I. (2003) The Association between Depression and Isotretinoin Usage in Acne. Australian \& New Zealand Journal of Psychiatry, 37, 78-84. https://doi.org/10.1046/j.1440-1614.2003.01111.x

[25] Wysowski, D.K., Pitts, M. and Beitz, J. (2001) An Analysis of Reports of Depression and Suicide in Patients Treated with Isotretinoin. Journal of the American Academy of Dermatology, 45, 515-519. https://doi.org/10.1067/mjd.2001.117730

[26] Wysowski, D., Pitts M. and Beitz J. (2001) Depression and Suicide in Patients Treated with Isotretinoin. New England Journal of Medicine, 344, 460-461. https://doi.org/10.1056/NEJM200102083440616

[27] Hull, P.R. and D'Arcy, C. (2003) Isotretinoin Use and Subsequent Depression and Suicide: Presenting the Evidence. American Journal of Clinical Dermatology, 4, 493-505. https://doi.org/10.2165/00128071-200304070-00005

[28] Bremner, J.D., Shearer, K.D. and McCaffery, P.J. (2012) Retinoic Acid and Affective Disorders: The Evidence for an Association. Journal of Clinical Psychiatry, 73, $37-$ 50. https://doi.org/10.4088/JCP.10r05993

[29] Bremner, J.D. (2008) The Neurobiology of Retinoic Acid in Affective Disorders. Progress in Neuro-Psychopharmacology \& Biological Psychiatry, 32, 315-331.

[30] Schaffer, L.C., Schaffer, C.B., Hunter, S. and Miller, A. (2010) Psychiatric Reactions to Isotretinoin in Patients with Bipolar Disorder. Journal of Affective Disorders, 122, 306-308.

[31] Azoulay, L., Blais, L., Koren, G., LeLorier, J. and Bérard, A. (2008) Isotretinoin Use and Risk of Depression, Psychotic Symptoms, Suicide, and Attempted Suicide. Journal of Clinical Psychiatry, 69, 526-532. https://doi.org/10.4088/JCP.v69n0403

[32] Kaymak, Y., Taner, E. and Taner, Y. (2009) Comparison of Depression, Anxiety and Life Quality in Acne Vulgaris Patients Who Were Treated with Either Isotretinoin or Topical Agents. International Journal of Dermatology, 48, 41-46. https://doi.org/10.1111/j.1365-4632.2009.03806.x

[33] Marqueling, A.L. and Zane, L.T. (2005) Depression and Suicidal Behavior in Acne Patients Treated with Isotretinoin: A Systematic Review. Seminars in Cutaneous Medicine and Surgery, 24, 92-102.

[34] Magin, P., Pond, D. and Smith, W. (2005) Isotretinoin, Depression and Suicide: A Review of the Evidence. British Journal of General Practice, 55,134-138. 
[35] Mallon, E., Newton, J.N., Klassen, A., Stewart-Brown, S.L., Ryan, T.J., et al. (1999) The Quality of Life in Acne: A Comparison with General Medical Conditions Using Generic Questionnaires. British Journal of Dermatology, 140, 672-676. https://doi.org/10.1046/j.1365-2133.1999.02768.x

[36] Kokandi, A. (2010) Evaluation of Acne Quality of Life and Clinical Severity in Acne Female Adults. Dermatology Research and Practice, 2010, Article ID: 410809. https://doi.org/10.1155/2010/410809

[37] Hanisah, A., Med, K.O. and Shah, S.A. (2009) Prevalence of Acne and Its Impact on the Quality of Life in School-Aged Adolescents in Malaysia. Journal of Primary Health Care, 1, 20-25.

[38] Lasek, R.J. and Chren, M. (1998) Acne Vulgaris and the Quality of Life of Adult Dermatology Patients. Archives of Dermatology, 134, 454-458.

https://doi.org/10.1001/archderm.134.4.454

[39] Akyazı, H., Baltac1, D., Alpay, K. and Hocaoğlu, C. (2011) Quality of Life in Adult Patients with Acne Vulgaris before and after Treatment. Dicle Medical Journal, 38, 282-288. https://doi.org/10.5798/diclemedj.0921.2011.03.0032

[40] Jafferany, M., Stoep, A.V., Dumitrescu, A. and Hornung, R.L. (2010) The Knowledge, Awareness, and Practice Patterns of Dermatologists toward Psychocutaneous Disorders: Results of a Survey Study. International Journal of Dermatology, 49, 784789. https://doi.org/10.1111/j.1365-4632.2009.04372.x

[41] Shenefelt, P.D. (2010) Psychological Interventions in the Management of Common Skin Conditions. Psychology Research and Behavior Management, 3, 51-63. https://doi.org/10.2147/PRBM.S7072

[42] Freedberg, I.M., Eisen, A.Z., Wolff, K., Stern, R.S. and Wintroub, B.U. (1999) Cutaneous Reactions to Drugs. In: Fitzpatrick's Dermatology in General Medicine, 5th Edition, McGraw-Hill, New York, 1633-1642.

[43] Mishra, B., Praharaj, S.K., Prakash, R. and Sinha, V.K. (2008) Aripiprazole-Induced Acneiform Eruption. General Hospital Psychiatry, 30, 479-481.

[44] Oztas, P., Aksakal, A.B., Oztas, M.O. and Onder, M. (2001) Severe Acne with Lithium. Annals of Pharmacotherapy, 35, 961-962. https://doi.org/10.1345/aph.10323

[45] Locala, J.A. (2009) Current Concepts in Psychodermatology. Current Psychiatry Reports, 11, 211-218. https://doi.org/10.1007/s11920-009-0033-x

[46] Mufaddel, A., Osman, O.T. and Almugaddam, F. (2013) Adverse Cutaneous Effects of Psychotropic Medications. Expert Review of Dermatology, 8, 681-692. https://doi.org/10.1586/17469872.2013.846515 
Submit or recommend next manuscript to SCIRP and we will provide best service for you:

Accepting pre-submission inquiries through Email, Facebook, LinkedIn, Twitter, etc. A wide selection of journals (inclusive of 9 subjects, more than 200 journals)

Providing 24-hour high-quality service

User-friendly online submission system

Fair and swift peer-review system

Efficient typesetting and proofreading procedure

Display of the result of downloads and visits, as well as the number of cited articles Maximum dissemination of your research work

Submit your manuscript at: http://papersubmission.scirp.org/

Or contact ojpsych@scirp.org 